http://jmscr.igmpublication.org/home/ ISSN (e)-2347-176x ISSN (p) 2455-0450 crossref DOI: https://dx.doi.org/10.18535/jmscr/v7i8.110

\title{
Room-air Pulse Oximetry: effects of Smoking, Age, Gender, Blood pressure, Respiratory rate and Body mass index
}

\author{
Authors \\ Dr Ali Al Bshabshe ${ }^{1}$, Dr Kamalasanan.C.G ${ }^{2^{*}}$, Dr Kiran.K ${ }^{3}$, Dr Awdah, Alkhathami ${ }^{4}$, \\ Dr Abdulrahman Qatomah ${ }^{5}$, Dr Abdulaziz Al Garni ${ }^{6}$, Dr Binda Devi ${ }^{7}$ \\ ${ }^{1}$ Associate Professor, Department of Internal Medicine, College of Medicine, King Khalid University, Abha, \\ Kingdom of Saudi Arabia \\ ${ }^{2}$ Additional Professor, Department of Internal medicine, Government Medical College, Calicut, Kerala, India \\ ${ }^{3}$ Senior Resident, Department of Surgical Oncology, Regional Cancer Centre, Trivandrum, Kerala, India \\ ${ }^{4,5,6}$ Resident, Department of Internal Medicine, College of Medicine, King Khalid University, Abha, \\ Kingdom of Saudi Arabia \\ ${ }^{7}$ Dermatology Consultant, Al Hayah National Hospital, Khamis Mushayt, Kingdom of Saudi Arabia \\ *Corresponding Author \\ Dr Kamalasanan. C.G
}

Additional Professor, Dept of Internal Medicine, Government Medical College, Calicut, 673008, Kerala, India

\begin{abstract}
Background: Hypoxemia is a serious situation; physical examination alone is insufficient to detectoxygenation failure. As oxygenation requirements are largely determined by pulse oximetry, vs. arterial blood gas, which is invasive and not a real-time technique. Various parameters are known to have effects on pulse oximetry values other than various disease processes. Before interpreting an abnormal pulse oximetry value, it will be prudent to know the effects of those personal parameters.

Methods: We sought to determine the distribution of oximetry $\left(\mathrm{SpO}_{2}\right)$ values in awake, asymptomatic adults, and the effect of personal characteristics like smoking, gender, respiratory rate, blood pressure, and body mass index (BMI) on these values.

It is a prospective cross-sectional study, sampling oximetry readings in adults without acute cardiac or pulmonary disease, who had no history of chronic lung disease. Participants were invited to participate if they were in normal health, as we excluded anyone with respiratory or cardiac symptoms.

Results: Data from 338 people in the southern region of Saudi Arabia were collected; seventy-five of them (22.2\%) were female and 263 (77.8\%) were male, mean age was 29.6 years. Smoking status: never smoked, 277 (82\%); previous smoker, 7 (2\%); current smoker, 54 (16\%). Room-air SpO $\mathrm{O}_{2}$ values of less than 92\% were noted in $6 \%$ of asymptomatic volunteers.

Statistical analysis showed no effects due to age $(p=0.27)$, smoking history $(p=0.69)$, gender $(p=0.33)$, blood pressure $(p=0.3)$, respiratory rate $(p=0.819)$, body mass index $(p=0.45)$ on $\mathrm{SpO}_{2}$ levels as assessed by room air pulse oximetry.

Conclusion: Personal characteristics, such as age, gender, smoking history, blood pressure, respiratory rate, and BMI had no effect on room-air $\mathrm{SpO}_{2}$ values.

Keywords: pulse oximetry; BMI; saturation; oxygen.
\end{abstract}




\section{Introduction}

Accurate and quick detection of hypoxemia is critical in preventing serious complications in critically ill patients. Clinical examination alone is not adequate to detect oxygen desaturation since cyanosis does not develop until the level of deoxyhemoglobin reaches $5 \mathrm{~g} / \mathrm{dL}$, which corresponds to arterial oxygen saturation $\left(\mathrm{SaO}_{2}\right)$ of approximately $67 \%^{[1]}$. Furthermore, the threshold at which cyanosis becomes apparent is affected by multiple variables, including peripheral perfusion, skin pigmentation, and haemoglobin concentration ${ }^{[2]}$.

Arterial blood gas analysis was the optimal technique for detecting hypoxemia in critically ill patients for many years, but it has potential complications and is unable to provide a continuous measurement ${ }^{[3]}$. Oxygen requirements can be determined using pulse oximetry, instead of arterial blood gas sampling. Pulse oximetry is a technique used to measure oxygen saturation $\left(\mathrm{SpO}_{2}\right)$ non-invasively. In addition, oxygen saturation is considered as the "fifth vital sign," as discussed in some of the literature and in clinical practice, which is documented in most patients while in the emergency room (ER $)^{[4]}$. Pulse oximetry is also helpful with many respiratory disorders, including pneumonia and pulmonary embolism $^{[7,8]}$. In clinical practice, oxygen saturation functions as a complementary parameter to vital signs, if it is not included as a fifth one. Our knowledge of pulse oximetry reference values in normal adults is somewhat limited. Therefore, should we consider different ranges of what constitutes normal for smokers and nonsmokers?

\section{Materials and Methods}

The Research and Ethics Committee approval was obtained to conduct the study. Using a crosssectional design, after obtaining consent, the subjects were initially asked whether they had any cardiac or respiratory symptoms: if they answered positive, they were excluded. Initially, we asked participants about coughing, shortness of breath, and chest pain, while pulse rate, respiratory rate, blood pressure, weight, and height were measured as well. Lastly, oxygen saturation was measured with a portable pulse oximeter (Smart signs Minipulse, Huntleigh Healthcare), and used for all subjects, thereby avoiding inter-device discrepancy. Smoking history was defined as someone being a current smoker, a previous smoker, which also included the type of smoking (cigarettes or other types).

Exclusion criteria for the study were strict, as we excluded those with temperature $>38^{\circ} \mathrm{C}$ or < $35^{\circ} \mathrm{C}$, respiratory rate $>25$ breaths $/ \mathrm{min}$, systolic blood pressure $<90$ or $>220 \mathrm{~mm} \mathrm{Hg}$, or diastolic blood pressure $>120 \mathrm{~mm} \mathrm{Hg}$.

The information was collected by one group of investigators, who used the same scale and height measurement device, as well as the same pulse oximeter device.

The team was instructed to avoid measuring oxygen saturation at the fingers with any nail polish or dye, as they can interfere with accurate measurements.

We agreed on acceptable readings for oxygen saturation after $30 \mathrm{~s}$ of the pulse oximeter being attached to the subjects' fingers (covered to avoid ambient light interference).

The primary goals of this study were to determine the distribution of oxygen saturation in asymptomatic adults and to find the effect of personal characteristics in $\mathrm{SpO}_{2}$ values. Statistical significance was defined as $p<.05$. Analyses was performed with statistics software Statistical Package for the Social Sciences (SPSS).

\section{Results}

Data from 338 healthy volunteers from the southern region of Saudi Arabia were collected over a 10-month period: of these, 75 (22.2\%) were female and $263(77.8 \%)$ were male, Fig 1. 
Fig 1: Gender Distribution

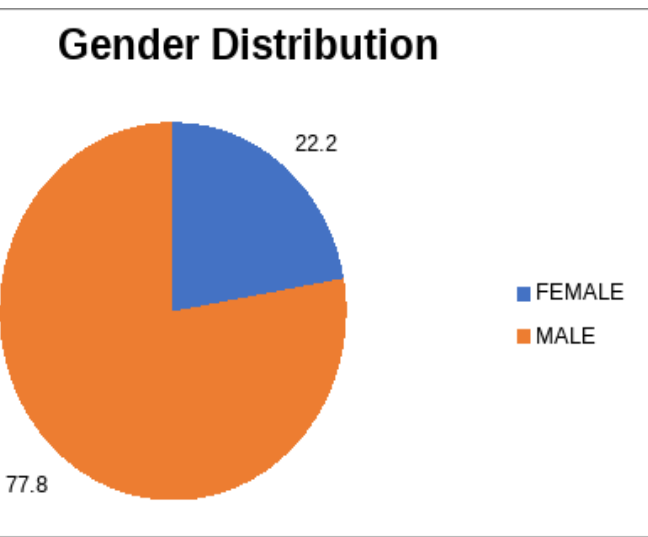

The mean age was 29.6 years, Table.1.

Table 1: Age Distribution

\begin{tabular}{|l|c|c|}
\hline Age in years & Freq. & \% \\
\hline $1-20$ & 68 & $20.12 \%$ \\
\hline $21-41$ & 205 & $60.65 \%$ \\
\hline $42-62$ & 58 & $17.16 \%$ \\
\hline Above 63 & 7 & $2.07 \%$ \\
\hline Total & 338 & $100.00 \%$ \\
\hline Mean & \multicolumn{2}{|c|}{29.58} \\
\hline SD & \multicolumn{2}{|c|}{12.74} \\
\hline
\end{tabular}

$277(82 \%)$ subjects werenever smokers, 7 (2\%) were previous smokers while $54(16 \%)$ were current smokers. BMIs were as follows: 18.5-24.9 (38\%), 25-29.9 (28.00\%), or more than $30(26 \%)$, with a mean BMI of 26.7, Table.2.

Table 2: BMI

\begin{tabular}{|l|l|l|l|}
\hline BMI & $15-18.5$ & 24 & $7 \%$ \\
\hline Underweight & $18.5-24.99$ & 130 & $38 \%$ \\
\hline Normal & $25-29.99$ & 96 & $28 \%$ \\
\hline Overweight & Above 30 & 55 & $16 \%$ \\
\hline Obese grade 1 & above 35 & 33 & $10 \%$ \\
\cline { 1 - 2 } Obese grade 2 & 338 & $100 \%$ \\
\cline { 1 - 2 } Total & & \\
\hline Mean 26.7,SD 6.7
\end{tabular}

The average room-air $\mathrm{SpO}_{2}$ was $95.8(\mathrm{SD}=2.74)$ Room-air $\mathrm{SpO}_{2}$ values less than $92 \%$ were noted in less than $6 \%$ of asymptomatic volunteers. The average respiratory rate, pulse rate, systolic and diastolic blood pressure were 21 breaths/min, 81 beats/min, $128 \mathrm{~mm} \mathrm{Hg}, 79 \mathrm{~mm} \mathrm{Hg}$, respectively. As depicted in Table 3, $\mathrm{SpO}_{2}$ has no significant relationship with age $(p=0.275), \mathrm{RR} \quad(p=0.819)$ with SBP $(p=0.305)$, with DBP $(p=0.724)$, and with BMI $(p=0.453)$.
Table 3: Relationship between Patient parameters and $\mathrm{SpO}_{2}$

\begin{tabular}{|c|c|c|}
\hline \multicolumn{3}{|l|}{ Respiratory Rate } \\
\hline C.I & Freq. & $\%$ \\
\hline $10-18$ & 246 & $72.78 \%$ \\
\hline $19-25$ & 85 & $25.15 \%$ \\
\hline above 25 & 7 & $2.07 \%$ \\
\hline Total & 338 & $100.00 \%$ \\
\hline \multicolumn{3}{|l|}{$\begin{array}{l}\text { Average }=21.3 \\
\text { S.D }=22.5\end{array}$} \\
\hline \multicolumn{3}{|l|}{ SBP } \\
\hline C.I & Freq. & $\%$ \\
\hline $1-120$ & 114 & $33.73 \%$ \\
\hline $121-139$ & 151 & $44.67 \%$ \\
\hline above 140 & 73 & $21.60 \%$ \\
\hline Total & 338 & $100.00 \%$ \\
\hline \multicolumn{3}{|l|}{$\begin{array}{l}\text { Average }=128.4 \\
\text { S.D }=16.2\end{array}$} \\
\hline \multicolumn{3}{|l|}{ DBP } \\
\hline C.I & Freq. & $\%$ \\
\hline below 40 & 4 & $1.18 \%$ \\
\hline $40-60$ & 12 & $3.55 \%$ \\
\hline $61-80$ & 180 & $53.25 \%$ \\
\hline $81-90$ & 85 & $25.15 \%$ \\
\hline above 90 & 57 & $16.86 \%$ \\
\hline Total & 338 & $100.00 \%$ \\
\hline \multicolumn{3}{|l|}{$\begin{array}{l}\text { Average }=78.9 \\
\text { S.D }=13.4\end{array}$} \\
\hline \multicolumn{3}{|l|}{$\mathrm{SpO}_{2}$} \\
\hline Range & Freq. & $\%$ \\
\hline $61-91$ & 14 & $4.14 \%$ \\
\hline $91-100$ & 324 & $95.86 \%$ \\
\hline Total & 338 & $100.00 \%$ \\
\hline $\begin{array}{l}\text { Average }=95.8 \\
\text { S.D }=2.74\end{array}$ & & \\
\hline
\end{tabular}

\section{Discussion}

In this study, we found that room-air $\mathrm{SpO}_{2}$ less than $92 \%$ was quite rare in awake, adult asymptomatic healthy volunteers; we suspect this was related to how the older volunteers were excluded if they had symptoms of cough, shortness of breath, or chest pain. By default, this left us with a younger population. Increasing age was a strong predictor of lower values of oxygen saturation, as reported in previous studies ${ }^{[9]}$, which included BMI, male gender, and smoking tendencies. We could not demonstrate this in our own study with a younger cohort, with a lower incidence of smoking. A healthy survivor effect and a decreased representation of those with poor health may have led to a healthier sample. This may explain why aging did not lead to decreased 
SpO2. Smoking is a strong predictor of acquiring chronic obstructive pulmonary disease and lower oxygen saturation ${ }^{[10]}$. Previous data on room-air pulse oximetry ${ }^{[11]}$ suggested that smoking was not associated with lower $\mathrm{SpO}_{2}$ values, which was consistent with our findings, although we were limited in the comparison between smokers (7\%) and nonsmokers (82\%), as most smokers were excluded in our study. We rarely found a smoker without cough, shortness of breath, or chest pain. We were surprised by the increased obesity in the community see Table 2. (Body mass index distribution, the prevalence of obesity was more than $70 \%$ in this cohort). This alerted us to the need for general health education about this disease. A similar finding was noted with the 'silent killer' hypertension, as its prevalence in healthy volunteers exceeded $68 \%$. Witting and his group did similar work to this study evaluating the room-air $\mathrm{SpO}_{2}$ values in asymptomatic, awake adults and they found that a white race and male sex are associated with lower $\mathrm{SpO}_{2}$ readings ${ }^{[11]}$. Obesity has a definite effect as per the observation by Kapur et $\mathrm{al}^{[12]}$. Smoking history and obesity are associated with low $\mathrm{SpO}_{2}$, while age and gender have no effect as per Vold et $\mathrm{al}^{[13]}$. Smoking reduces oxygen saturation as per the study by Ozdal et $\mathrm{al}^{[14]}$. Age influences pulse oximetry but not gender as per a study by Bhogal et al ${ }^{[15]}$.

\section{Conclusion}

Personal characteristics such as age, gender, smoking history, blood pressure, respiratory rate, and BMI had no effect on room-air $\mathrm{SpO}_{2}$ values.

\section{References}

1. Grace, RF. Pulse oximetry: Gold standard or a false sense of security? Med J Aust 1994;160:638.

2. Hanning, CD, Alexander-Williams, JM. Pulse oximetry: A practical review. Brit Med J1995; 311:367.

3. Pierson, DJ. Pulse oximetry versus arterial blood gas specimens in long-term oxygentherapy. Lung 1990;

168

Suppl:782.

4. Mower WR, Myers G, Nicklin EL, et al. Pulse oximetry as a fifth vital sign inemergency geriatric assessment. Acad Emerg Med 1998; 5:858-65.

5. Mower WR, Sachs C, Nicklin EL, et al. Pulse oximetry as a fifth pediatric vital sign.Pediatrics 1997; 99:681-6.

6. Tierney Jr LM, Whooley MA, Saint S. Oxygen saturation: a fifth vital sign. West J Med1997; 166:285-6.

7. Kline JA, Nelson RD, Jackson RE, et al. Criteria for the safe use of D-dimer testing inemergency department patients with suspected pulmonary embolism: a multicenterUS study. Ann Emerg Med 2002; 39:144-52.

8. Kaye KS, Stalam M, Shershen WE, et al. Utility of pulse oximetry in diagnosingpneumonia in nursing home residents. Am J Med Sci 2002; 324:23742.

9. Vold ML, Aasebo U, Hjalmarson A, Melbye H. Predictors of oxygen saturation less than 95\% in a cross-sectional population-based survey. Resp Med 2012; 106(11):1551-8.

10. Forey BA, Thornton AJ, Lee PN. Systematic review with meta-analysis of the epidemiological evidence relating smoking to COPD, chronic bronchitis, and emphysema. BMC Pulmonary Med 2011; 11:36.

11. Witting MD, Scharf, SM. Diagnostic room-air pulse oximetry: effects of smoking, race, and sex. Am J Emerg Med 2008; 26:131-136.

12. Vishesh K Kapur, Anthony G Wilsdon , David Au , Mark Avdalovic et al. Obesity Is Associated With a Lower Resting Oxygen Saturation in the Ambulatory Elderly: Results From the Cardiovascular Health Study. Respir Care 2013;58(5):831-837. 
13. Monica Linea Vold, Ulf Aasebo, Hasse Melbye. Low FEV1, smoking history, and obesity are factors associated with oxygen saturation decrease in an adult population cohort. International Journal of COPD 2014:9 1225-1233.

14. Mustafa Ozdal, Zarife Pancar, Vedat Çinar, Murat Bilgiç. Effect of Smoking on Oxygen Saturation in Healthy Sedentary Men and Women.EC Pulmonology and Respiratory Medicine 4.6 (2017): 178-182.

15. Bhogal AS Mani AR. Pattern Analysis of Oxygen Saturation Variability in Healthy Individuals: Entropy of Pulse Oximetry Signals Carries Information about Mean Oxygen Saturation. Front. Physiol. 8:555.doi: 10.3389/fphys.2017.00555. 